\title{
Outstanding Reviewers and Associate Editors for 2011
}

The objective of this note is to thank all our reviewers and editors for their hard work in 2011. Our editorial team reviewed a total of 819 manuscripts, with a turnaround time of only 13.9 days from the date of invitation. As we are all volunteers, this hard work reflects our community's passion and love for our profession and, especially, its flagship journal. Our commitment is to elevate our Society's flagship journal to the very top of scientific publications. Although all of our reviewers and editors contributed to our excellence last year, we would like to honor those with particularly noteworthy accomplishments. Each of them received a special certificate. Here is the list:

\section{REVIEWERS}

Top Reviewer

Steven Rowson, Virginia Tech, Blacksburg, VA, USA

Reviewer Excellence

Louis DeFrate, Duke University, Durham, NC, USA
F. Scott Gayzik, Virginia Tech - Wake Forest University, Winston-Salem, NC, USA

Alberto Avolio, Macquarie University, Sydney, Australia

Kinon Chen, University of British Columbia, Vancouver, Canada

\section{ASSOCIATE EDITORS}

Editorial Excellence

Stefan Duma, Virginia Tech, Blacksburg, VA, USA

John Linehan, Northwestern University, Chicago, IL, USA

Nathalie Virag, Medtronic Europe, Tolochenaz, Switzerland

Thanks to all of our readers, authors, reviewers, and editors for your enthusiastic support.

K. A. Athanasiou 